\title{
THE ANALYSIS OF TRIBOLOGICAL PROCESSES IN THE INKING UNIT OF THE OFFSET PRINTING MACHINE
}

\author{
Yuriy PYRYEV * Zofia Maria PIĘTAK *
}

* Faculty of Production Engineering, Institute of Mechanics and Printing, Division of Graphic Art Technologies, Warsaw University of Technology, ul. Konwiktorska 2, 00-217 Warszawa, Poland

yu_pyryev@wp.pl, z.pietak@gmail.com

\begin{abstract}
In this paper is proposed the mathematical description of the temperature distribution resulting from the friction between the two inking rollers (one of which is made off steel and the second one has elastic layer) in the offset printing machine. So-called in printing industry steel vibrator roller perform simultaneously rotary and reciprocating motion. This reciprocating motion is the main source of the heat generation. Using the Laplace transform method for heat conduction equations with boundary conditions taking into account the real processes taking place in the inking unit in contact area we obtained and analyzed the solution that could be useful for determination and regulation of parameters in order to decrease time of process stabilization.
\end{abstract}

Key words: Printing, Friction, Inking Unit, Laplace Transform, Heat Distribution, Roller/Roller Contact

\section{INTRODUCTION}

During the printing process in the offset printing machine, temperature of the rollers in the inking unit and surrounding air increases gradually. This phenomena bases on the influence of the pressure between rotating rigid steel and rubber coated rollers and influence of the reciprocating motion along the roller pivot. The phenomena of temperature variations in the inking unit of the printing machines, particularly the offset printing machines which are characterised by a complex inking unit, is inevitable. Even in the machines, in which the inking units (more precisely selected inking rollers) are thermostatted, the fluctuations of the temperature are considerable (Chou et al., 1996). The main cause of temperature increase in the inking unit is the friction between the flexible and rigid axially oscillating rollers. Temperature variations affect the quality of prints. The temperature increase in the inking unit leads to:

- changes of the rheological ink properties (especially viscosity);

- the instability of emulsion of ink and dampening solution;

- the deposition of dust on a rubber blanket;

- increased demand for dampening solution.

This all negatively affects quality of prints. Therefore it seems to be important and reasonable to study this phenomena more carefuly and to built and solve the appriopriate mathematical model. Mathematical models describing the various processes in the mechanical frictional contact presented by Awrejcewicz et al. (2013), Olejnik et al. (2013), Talati et al. (2009), Yevtushenko et al. $(2009,2012)$ were studied in order to compare various approaches and choose the own path.

\section{GEOMETRY AND ASSUMPTIONS OF MODEL}

In the inking unit of the offset press the ink is transported from the ink fountain to the plate cylinder through a set of rotating and being in contact rigid and covered with flexible layer rollers. Par- ticular importance for the warm-up phenomenon have steel vibrator rollers which simultaneously perform a rotary (frequency $\Omega$ ) and reciprocating motion.

Due to the high real speed of rotating rollers (rigid vibrator roller is cooled by the liquid flowing inside the roller), the problem of the roller pair is simplified and reduced to the problem of the roller with liquid coolant inside $T_{1}^{0}(t)=\theta_{1}^{0} h_{1}(t)$ and roller's surrounding, which on the border with the surrounding reaches the temperature ambient (surrounding) temperature $T_{2}^{0}(t)=$ $\theta_{2}^{0} h_{2}(t)$ (Pyryev et al., 2010). The generated heat is a result of friction on the contact surface between rollers. The heat flux acts on the border of the roller $R=R_{0}$ and surrounding (Fig. 1).

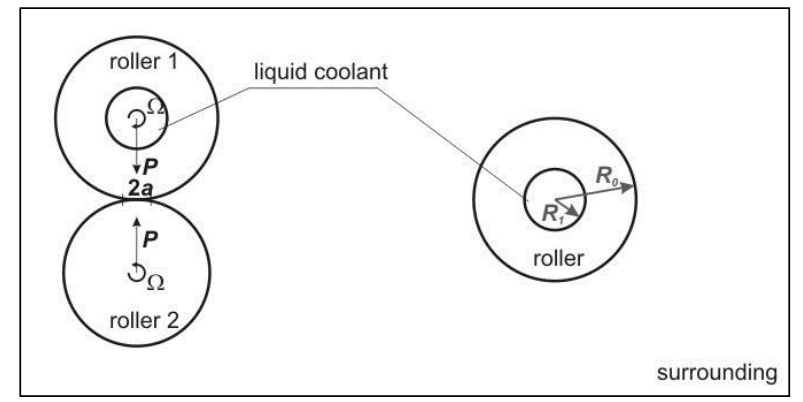

Fig. 1. The transition from the real issue to the model

In the case of axisymmetric state of roller temperature $T_{1}$ state the heat conduction equation for an isotropic body in cooperation with cylindrical coordinates $(R, \varphi, z)$ given by Carslaw et. al (1959) will take the form as follows:

$$
\frac{\partial^{2} T_{1}(R, t)}{\partial R^{2}}+\frac{1}{R} \frac{\partial T_{1}(R, t)}{\partial R}=\frac{1}{k_{1}} \frac{\partial T_{1}(R, t)}{\partial t}, R_{1}<R<R_{0}
$$

with following boundary conditions (after Awrejcewicz et al., 2009): 
$\lambda_{1} \frac{\partial T_{1}\left(R_{1}, t\right)}{\partial R}-\alpha_{1}^{T}\left[T_{1}\left(R_{1}, t\right)-\theta_{1}^{0} h_{1}(t)\right]=0$

$\lambda_{1} \frac{\partial T_{1}\left(R_{0}, t\right)}{\partial R}+\alpha_{2}^{T}\left[T_{1}\left(R_{1}, t\right)-\theta_{2}^{0} h_{2}(t)\right]=Q(t)$

and initial conditions:

$$
T_{1}(R, 0)=0, R_{1}<R<R_{0}
$$

Above we have taken indications as follows: $T_{1}(R, t)-$ temperature increase of the roller, $t$ - time, $Q(t)=\theta_{0}^{0} h_{0}(t)-$ power density of friction, $k_{1}$ - thermal diffusivity of a roller, $\alpha_{n}^{T}$ heat transfer coefficient: $(n=1)$ between the coolant and material which the roller is made of (forced water flow in the pipe), $(n=2)$ between the surrounding (air) and material which the roller is made of (forced air flow near the surface of the roller), $\lambda_{1}$ - thermal conductivity of the roller, $h_{n}(t)$ - dimensionless internal $(n=1)$ and external $(n=2)$ temperature, $T_{1}^{0}(t)=\theta_{1}^{0} h_{1}(t)$, $T_{2}^{0}(t)=\theta_{2}^{0} h_{2}(t)$ - temperature increase of the coolant and sorrounding.

We assume that the reciprocating movement (and resulted from it friction) is the source of heat, and hence we assumed the formula of the friction power density:

$$
Q(t)=\left(1-\eta_{1}\right) \eta_{2} f\left(V_{r}\right) V_{r} p_{0}
$$

where: $p_{0}$ - average contact pressure, associated with a contact force $P$ by formula $p_{0}=P / 2 a$, where contact area width $2 a$ is found from Herz problem solution for two rollers (Jurkiewicz et al., 2011), $V_{r}$ - relative velocity of being in contact rollers, $f\left(V_{r}\right)$ - kinematic friction coefficient, $\eta_{1}$ - coefficient responsible for the part of the power which is lost e.g. because of wear, $\eta_{2}$ - coefficient depending on time.

After Blok (1940) we assume that kinematic friction coefficient: $f\left(V_{r}\right)=f_{0} \operatorname{sgn}\left(V_{r}\right)$ and therefore we obtain:

$$
Q(t)=\left(1-\eta_{1}\right) \eta_{2} f_{0}\left|V_{r}\right| p_{0}
$$

The construction and operation of the inking unit (rotary and reciprocating motion of the roller) results that the relative movement of being in contact rollers along the axis changes periodically:

$$
Z(t)=Z_{0} \sin \omega t
$$

where: - maximum relative displacement of the rollers, $\omega$ frequency of relative displacement of rollers (from the construction of the inking unit $\omega=\Omega$ ).

The fact that the heat is generated by friction in changing contact area:

$$
S(t)=2 a(L-|Z(t)|)
$$

where: $S(t)$ - contact area between rollers, $L$ - length of the roller,is included by entering the depending on the time coefficient $\eta_{2}$ into the formula (6) of the heat flux $Q(t)$ :

$$
\eta_{2}=S(t) / S_{1}
$$

where: $S_{1}$ - area of the cylinder side $S_{1}=2 \pi R_{0} L$.

Hence the coefficient:

$$
\eta_{2}=\frac{2 a(L-|Z(t)|)}{2 \pi R_{0} L}=\frac{a}{\pi R_{0}}\left(1-\frac{Z_{0}}{L}|\sin \omega t|\right)
$$

The heat flux can now be written as:

$$
Q(t)=\left(1-\eta_{1}\right) \frac{a f_{0} \omega Z_{0} p_{0}}{\pi R_{0}}\left(1-\frac{Z_{0}}{L}|\sin \omega t|\right)|\cos \omega t|
$$

Assuming:

$$
Q(t)=\theta_{0}^{0} h_{0}(t) \text { i } z_{0}=\frac{Z_{0}}{L}
$$

we obtain:

$$
\begin{aligned}
& \theta_{0}^{0}=\left(1-\eta_{1}\right) \frac{a f_{0} \omega Z_{0} p_{0}}{\pi R_{0}} \\
& h_{0}(t)=\left(1-z_{0}|\sin \omega t|\right)|\cos \omega t|
\end{aligned}
$$

Below, in Fig. 2, there is shown an exemplary graph of the function $h_{0}(t)$ for $z_{0}=0.2$.

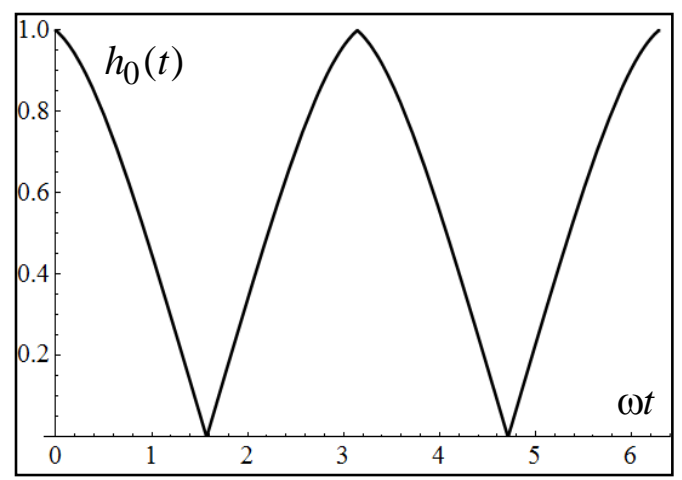

Fig. 2. The evolution of the heat flux due to the rollers' reciprocation motion

\section{NON-STATIONERY SOLUTION}

On the proposed model equation (1) we perform Laplace transform (Carslaw et al., 1959; Abramowitz et al., 1965) defined by the relationship ( $s$ - transform parameter):

$$
\left\{\bar{T}_{1}(R, s), \bar{h}_{n}(s), \bar{Q}(s)\right\}=\int_{0}^{\infty}\left\{T_{1}(R, t), h_{n}(t), Q(t)\right\} e^{-s t} d t
$$

As a result of the Laplace transform we obtain second-order differential equation (modified Bessel equations):

$$
\frac{\partial^{2} \bar{T}_{1}(R, s)}{\partial R^{2}}+\frac{1}{R} \frac{\partial \bar{T}_{1}(R, s)}{\partial R}=\frac{s}{k_{1}} \bar{T}_{1}(R, s), R_{1}<R<R_{0}
$$

and boundary conditions:

$$
\begin{aligned}
& \lambda_{1} \frac{\partial \bar{T}_{1}\left(R_{1}, s\right)}{\partial R}-\alpha_{1}^{T}\left[\bar{T}_{1}\left(R_{1}, s\right)-\bar{T}_{1}^{0}(s)\right]=0 \\
& \lambda_{1} \frac{\partial \bar{T}_{1}\left(R_{0}, s\right)}{\partial R}+\alpha_{2}^{T}\left[\bar{T}_{1}\left(R_{0}, s\right)-\bar{T}_{2}^{0}(s)\right]=\bar{Q}(s)
\end{aligned}
$$

The general solution of the equations system (16)-(18) has the form (Carslaw et al., 1959; Abramowitz et al., 1965):

$$
\bar{T}_{1}\left(R_{1}, s\right)=C_{3}^{1} I_{0}\left(q_{1} R\right)+C_{4}^{1} K_{0}\left(q_{1} R\right), q_{1}=\sqrt{\frac{s}{k_{1}}}
$$


We find required differential (Abramowitz et al., 1965):

$\frac{d \bar{T}_{1}(R, s)}{d R}=q_{1} C_{3}^{1} I_{1}\left(q_{1} R\right)-q_{1} C_{4}^{1} K_{1}\left(q_{1} R\right)$

After introducing equations (19)-(20) into the boundary conditions (17)-(18) we get a set of two equations with two unknowns: $C_{1}^{1}$ and $C_{2}^{1}$ :

$\lambda_{1}\left(s_{1} C_{3}^{1} I_{1}\left(s_{1} R_{1}\right)-s_{1} C_{4}^{1} K_{1}\left(s_{1} R_{1}\right)\right)-$

$\alpha_{1}^{T}\left(C_{3}^{1} I_{0}\left(s_{1} R_{1}\right)+C_{4}^{1} K_{0}\left(s_{1} R_{1}\right)\right)=-\alpha_{1}^{T} \theta_{1}^{0} \bar{h}_{1}(s)$

$\lambda_{1}\left(s_{1} C_{3}^{1} I_{1}\left(s_{1} R_{0}\right)-s_{1} C_{4}^{1} K_{1}\left(s_{1} R_{0}\right)\right)+$

$\alpha_{2}^{T}\left(C_{3}^{1} I_{0}\left(s_{1} R_{0}\right)+C_{4}^{1} K_{0}\left(s_{1} R_{0}\right)\right)=+\alpha_{2}^{T} \theta_{2}^{0} \bar{h}_{2}(s)+\bar{Q}(s)$

By entering constants obtained from the equations (21)-(22) into the general solution (19) we receive the final solution and write it in form:

$\bar{T}_{1}(R, s)=\sum_{n=0}^{2}\left[\frac{\bar{\theta}_{1 n}(R, s)}{\Delta(s)} \theta_{n}^{0} \bar{h}_{n}(s)\right]$

where: $\Delta(s)=B i_{2} Q_{2}^{(1)}\left(R_{0}, R_{1}, s\right)+Q_{1}^{(1)}\left(R_{0}, R_{1}, s\right)$

$\bar{\theta}_{10}(R, s)=R_{0} \lambda_{1}^{-1} Q_{2}^{(1)}\left(R, R_{1}, s\right)=\left(\alpha_{2}^{T}\right)^{-1} B i_{2} Q_{2}^{(1)}\left(R, R_{1}, s\right)$

$\bar{\theta}_{11}(R, s)=B i_{1} Q_{1}^{(2)}\left(R_{0}, R, s\right), \bar{\theta}_{12}(R, s)=B i_{2} Q_{2}^{(1)}\left(R, R_{1}, s\right)$

$Q_{2}^{(1)}(x, y, s)=B i_{1} Z_{00}^{(1)}(x, y, s)+Z_{10}^{(1)}(y, x, s)$

$Q_{1}^{(2)}(x, y, s)=B i_{2} Z_{00}^{(1)}(x, y, s)+Z_{10}^{(1)}(x, y, s)$

$Z_{00}^{(1)}(x, y, s)=I_{0}\left(q_{1} x\right) K_{0}\left(q_{1} y\right)-I_{0}\left(q_{1} y\right) K_{0}\left(q_{1} x\right)$

$Z_{11}^{(1)}(x, y, s)=I_{1}\left(q_{1} x\right) K_{1}\left(q_{1} y\right)-I_{1}\left(q_{1} y\right) K_{1}\left(q_{1} x\right)$

$Z_{10}^{(1)}(x, y, s)=q_{1} x\left(I_{1}\left(q_{1} x\right) K_{0}\left(q_{1} y\right)+I_{0}\left(q_{1} y\right) K_{1}\left(q_{1} x\right)\right)$

By entering obtained from set of equations (21)-(22) constants into general solution (20) we receive the form of heat flux:

$\bar{Q}_{1}(R, s)=\lambda_{1} \frac{\partial \bar{T}_{1}(R, s)}{\partial R}=\sum_{n=0}^{2}\left[\frac{\bar{Q}_{1 n}(R, s)}{\Delta(s)} \theta_{n}^{0} \bar{h}_{n}(s)\right]$

where:

$$
\begin{aligned}
& \bar{Q}_{10}(R, s)=\lambda_{1} R_{0}\left(B i_{1} Z_{10}^{(1)}\left(R, R_{1}, s\right) / R-q_{1} q_{1} R_{1} Z_{11}^{(1)}\left(R_{1}, R, s\right)\right) \\
& \bar{Q}_{11}(R, s)=\lambda_{1} B i_{1} Q_{1}^{(2)}\left(R_{0}, R, s\right)= \\
& =\lambda_{1} B i_{1}\left(-B i_{2} Z_{10}^{(1)}\left(R, R_{0}, s\right) / R-q_{1} q_{1} R_{0} Z_{11}^{(1)}\left(R_{0}, R, s\right)\right) \\
& \bar{Q}_{12}(R, s)=\lambda_{1} B i_{2} Q_{2}^{(1)}\left(R, R_{1}, s\right)= \\
& =\lambda_{1} B i_{2}\left(B i_{1} Z_{10}^{(1)}\left(R, R_{1}, s\right) / R-q_{1} q_{1} R_{1} Z_{11}^{(1)}\left(R_{1}, R, s\right)\right) \\
& Q_{2}^{(1)}(x, y, s)=B i_{1} Z_{00}^{(1)}(x, y, s)+Z_{10}^{(1)}(y, x, s) \\
& Q_{1}^{(2)}(x, y, s)=B i_{2} Z_{00}^{(1)}(x, y, s)+Z_{10}^{(1)}(x, y, s)
\end{aligned}
$$

Above we have taken indications as follows: $I_{m}(z), K_{m}(z)$ modified $m$ th-order Bessel functions, of first and second kind respectively Abramowitz et al., 1965), $B_{i 1}=R_{1} \alpha_{1}^{T} / \lambda_{1}, B_{i 2}=$ $R_{0} \alpha_{2}^{T} / \lambda_{1}$ - Biot's numbers (Carslaw et al., 1959). Temperature transform $\bar{T}_{1}(R, s)$ and heat flux transform have been written in forms (23) and (24) by means of functions $Z_{m l}^{(n)}(x, y, s)$, which are defined above.

The Laplace transform of periodic function (14) has the form:

$$
\bar{h}_{0}(s)=\frac{2 \omega e^{\pi s / 2 \omega}-s+s e^{\pi \mathrm{s} / \omega}}{\left(e^{\pi \mathrm{s} / \omega}-1\right)\left(s^{2}+\omega^{2}\right)}-\frac{3 z_{0}\left(e^{\pi \mathrm{s} / 2 \omega}+1\right)}{\left(e^{\pi s / 2 \omega}-1\right)\left(s^{2}+4 \omega^{2}\right)}
$$

\section{ANALYSIS}

The analysis of obtained Laplace transforms shows that the peculiarities of these transforms can be only zero points of the characteristic function $\Delta(s)$ and the peculiarities of Laplace transforms $\bar{h}_{n}(s)$.

Using the Laplace transform method and Borel convolution theorem we find the solution and write roller temperature and the heat flux in the forms as follows (Piętak et al., 2011; Jurkiewicz et. al., 2011):

$$
\begin{aligned}
& T_{1}(R, t)=\sum_{n=0}^{2}\left[\frac{\bar{\theta}_{1 n}(R, 0)}{\Delta(0)}+\sum_{k=1}^{\infty} \frac{\bar{\theta}_{1 n}\left(R, s_{k}\right)}{s_{k} \Delta^{\prime}\left(s_{k}\right)} \exp \left(s_{k} t\right)\right] * \\
& \frac{d}{d t}\left(\theta_{n}^{0} h_{n}(t)\right) \\
& Q_{1}(R, t)=\sum_{n=0}^{2}\left[\frac{\bar{Q}_{1 n}(R, 0)}{\Delta(0)}+\sum_{k=1}^{\infty} \frac{\bar{Q}_{1 n}\left(R, s_{k}\right)}{s_{k} \Delta^{\prime}\left(s_{k}\right)} \exp \left(s_{k} t\right)\right] * \\
& \frac{d}{d t}\left(\theta_{n}^{0} h_{n}(t)\right)
\end{aligned}
$$

where: $\Delta^{\prime}\left(s_{k}\right)=d \Delta(s) /\left.d s\right|_{s=s_{k}}$.

Roots $s_{k}$ of the characteristic equation $\Delta(s)=0$ lie on the negative part of the real axis of complex plane of Laplace transform parameter, i.e.: $s_{k}=-\mu_{k}^{2}$.

For example, the thermostatted vibrator roller in the machine Heidelberg XL105 (according to technical drawing) has a diameter $2 R_{0}=84.8 \cdot 10^{-3} \mathrm{~m}$ and length $L=1085 \cdot 10^{-3} \mathrm{~m}$, width of the contact zone $2 a=5 \cdot 10^{-3} \mathrm{~m}$, displacement of the roller along the axis $z_{0}=17.5 \cdot 10^{-3} \mathrm{~m}$, coolant flow diameter $2 R_{1}=15 \cdot 10^{-3} \mathrm{~m}$. We assume that:

- the roller is made of steel (according to VanSant (1983): $\left.\lambda_{1}=21 \mathrm{~W} /\left(\mathrm{m}^{\circ} \mathrm{C}\right), k_{1}=0.7 \cdot 10^{-5} \mathrm{~m}^{2} / \mathrm{s}\right)$;

- the cooling fluid is the water at a temperature $\theta_{1}^{0} h_{1}(t)$ under conditions of forced flow into the pipe $\left(\alpha_{1}^{T}=2000 \mathrm{~W} /\right.$ $\left(m^{\circ} \mathrm{C}\right)$ );

- and the surrounding is the air at the temperature $\theta_{2}^{0} h_{2}(t)$ under conditions of forced flow near the surface of the roller $\left(\alpha_{2}^{T}=10 \mathrm{~W} /\left(\mathrm{m}^{\circ} \mathrm{C}\right)\right)$.

The preliminary analysis was performed for the case when functions $h_{n}(t)$ for $n=0,1,2$ are Heaviside step functions $H(t)(H(t)=0$ for $t<0$ and $H(t)=1$ for $t<0)$. Instead of periodic function $h_{0}(t)$ with the period $\pi / \omega$ we took in to account also the Heviside function $H(t)$ with the amplitude equel to the average value $h_{0}$ of this function:

$h_{0}=\frac{\omega}{\pi} \int_{0}^{\pi / \omega} h_{0}(t) d t=\frac{2-z_{0}}{\pi}$

We examine the case where at the surface of the roller $R=R_{0}$ due to the friction acts the heat flux $Q$ with amplitude $\theta_{0}^{0}=4000 \mathrm{~W} / \mathrm{m}^{2}$, the surrounding temperature increases in amount of $\theta_{2}^{0}=5^{\circ} \mathrm{C}$, and the coolant temperature is lower in amount of $\theta_{1}^{0}=-20^{\circ} \mathrm{C}$. 
First roots of the characteristic equation $\Delta(s)=0$ are as follows: $\quad s_{1}=-3.39 \cdot 10^{-3}, \quad s_{2}=-8.55 \cdot 10^{-2}, \quad s_{3}=$ $-2.68 \cdot 10^{-1}, \quad s_{4}=-5.57 \cdot 10^{-1}, \quad s_{5}=-9.57 \cdot 10^{-1}$, $s_{6}=-1.47, s_{7}=-2.09, s_{8}=-3.83$.

Taking into account the the first 17 roots of the chareacteristic equation in the formula (26) we show in Fig. 3 the evolution of the changes in the temperature of the roller surface $R=R_{0}$ (curve 1).

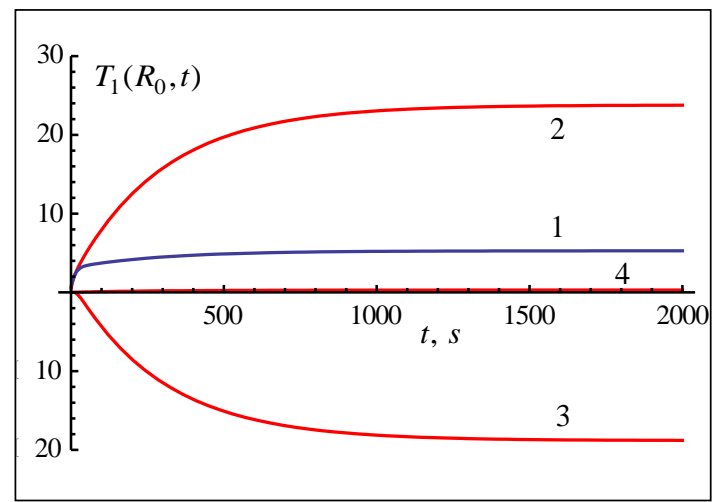

Fig. 3. The evolution of temperature changes at the roller surface $R=R_{0}$

Curve 2 presents roller surface temperature changes in case when the surrounding temperature increase and the coolant temperature change are both zero. The change of the roller surface temperature $\left(R=R_{0}\right)$ in time in case when there is no friction and no changes of the surrounding temperature shows the curve 3 in Fig. 3. The change in roller surface temperature $\left(R=R_{0}\right)$ caused by the increase of the surrounding temperature illustrates the curve 4 in Fig. 3.

The evolution of the roller temperature at surface $R=R_{1}$ we present in Fig. 4 (curve 1). Curve 2 in Fig. 4 describes evolution of roller internal surface $\left(R=R_{1}\right)$ temperature which is a result of the heat flux operating at the surface $R=R_{0}$ in case when the surrounding temperature is constant $\left(\theta_{1}^{0} h_{1}(t)=0\right)$ and there is no change in the coolant temperature. Changes in the temperature at internal roller surface in case when there is no friction and no changes in surrounding temperature are presented by curve 3 in Fig. 4 . Changes in the temperature at internal surface $R=R_{1}$ caused by increase in the surrounding temperature shows curve 4 in Fig. 4.

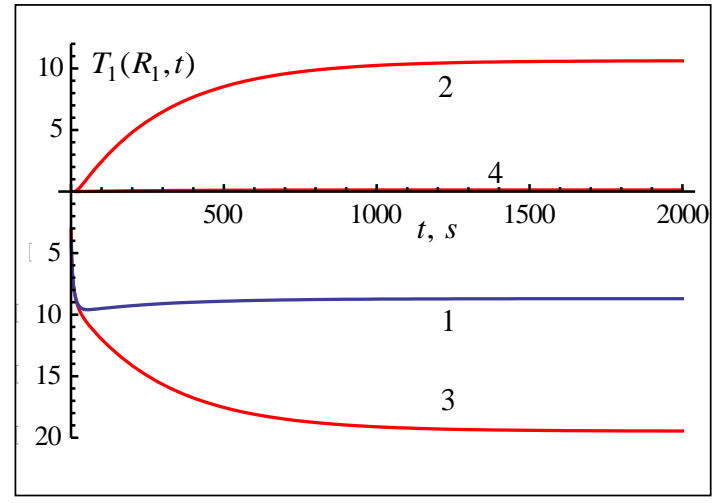

Fig. 4. The evolution of temperature changes at the roller surface $R=R_{1}$
The roller temperature distribution $T_{1}(R, t)$ along the roller radius $R$ is shown in Fig. 5. Curves 1-5 correspond to the temperature distribution, respectively at time $t=10,50,100$, $500,2000 \mathrm{~s}$.

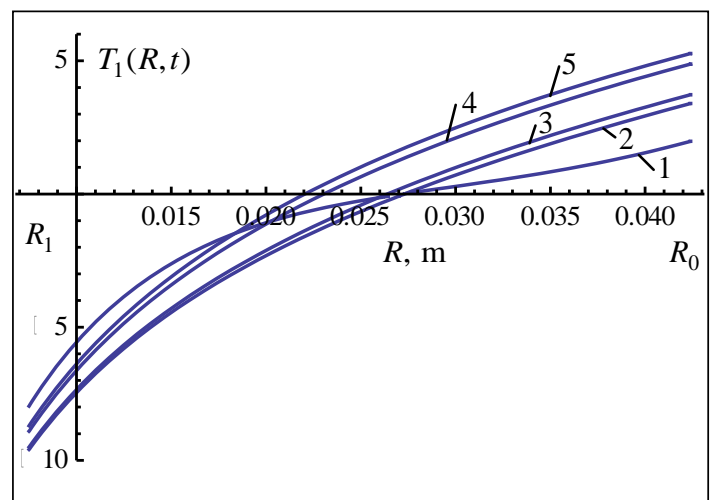

Fig. 5. The temperature distribution along the roller radius at different time instants

\section{CONCLUSIONS}

We obtain an analytical solution of the heat conduction problem for the inking unit in the offset printing machine. It has been proven that the functions $Z_{m l}^{(n)}(x, y, s)$, which we entered into transforms' formulas of the roller temperature (23) and the heat flux (24), are analytic functions.

It is worth noting, that the first terms of obtained formulas of roller temperature (26) and heat flux (27) corresponds to the stationary solution $(t \rightarrow \infty$ of this problem received in the earlier work (Piętak et al., 2011) for the case when the functions $h_{n}(t)$ where $n=0,1,2$ are Heaviside step functions (unit step function).

We assume that the inking is at temperature $22^{\circ} \mathrm{C}$. During the printing process (when machine is working) the heat flux is generated at the surface of the vibrator roller $\left(R=R_{0}\right)$ as a result of friction. The heat flux causes heating of the roller. If there is no cooling, the temperare increase overe time in amount of $24^{\circ} \mathrm{C}$ and reaches the level of $46^{\circ} \mathrm{C}$ (curve 2, Fig. 3). Offset printing technology requires lower temperature of the roller surface and of the ink transported by the roller. Therfore, in modern inking units rollers are thermostatted. When we take into account the coolant inside the roller we receive an increase of roller surface temperature in amount of only $5^{\circ} \mathrm{C}$ (curve 1 in Fig. 3). This way our model allows to simulate the temperature distribution in one of the elements of the prinitng unit of the offset printing machine and to regulate coolant temperature depending on the surrounding temperature changes and printing parameters, such as speed and properties of the ink.

The obtained solution makes it possible to determine and to regulate the time necessary to reach the stationery coditions of the temperature. Stationery conditions of the temeperature gurantee the stability of the printing process and less paper waste. In this way we can affect the amount of foracasted paper and ink waste.

We woluld like also notice that various forms of solutions for the cylinder (roller) are showed, e.g. in works of Carslaw et al. (1959) and VanSant (1983). 


\section{REFERENCES}

1. Abramowitz M, Stegun I. (1965) Handbook of mathematical functions: with formulas, graphs, and mathematical tables, Dover Publications Inc., New York

2. Awrejcewicz J., Grzelczyk D. (2013) Modeling and analysis of thermal processes in mechanical friction clutch-numerical and experimental investigations, International Journal of Structural Stability and Dynamics, Vol. 13, No. 7, 1340004-1-18.

3. Awrejcewicz J., Pyryev Y. (2009) Nonsmooth Dynamics of Contacting Thermoelastic Bodies, Springer Varlag.

4. Blok H. (1940) Fundamental mechanical aspects of boundary lubrication, S.A.E. J., 40, 2, 54-68.

5. Carslaw H. S., Jaeger J. C. (1959) Conduction of heat in solids, Clarendon Pres, Oxford.

6. Chou, S.M., L.J. Bain, R. Durand, Sanderson E. (1996) Novel printing press for waterless lithography. In: TAPPI Proceedings, International Printing \& Grpahic Arts Conference. Atlanta, 165-174.

7. Jurkiewicz A., Krzyżkowski J., Piętak Z., Pyr’yev Y. (2011) Modeling of selected phenomena which occur in offset printing presses, [In:] Scientific basis of modern technologies: experience and prospects, Shalapko Y. I., Dobrzanski L. A., Jaremche, 154-168.

8. Olejnik P., Awrejcewicz J. (2013) Low-speed voltage-input tracking control of a DC-motor numerically modelled by a dynamical system with stick-slip friction, Differential Equations and Dynamical Systems, Vol. 21, No. 1-2, 3-13.
9. Piętak Z. M., Pyryev Y. (2011) Mathematical modelling and description of friction and temperature phenomena in inking unit of the offset printing machine, Challenges of Modern Technology, Vol. 2, No. 1, 41-44.

10. Pyryev Y., Piętak Z.M. (2010) Modelowanie i opis matematyczny zjawisk tarciowych $\mathrm{w}$ zespole farbowym offsetowej maszyny drukującej, VI International Conference "Friction 2010". Modelling and Simulation of the Friction Phenomena in the Physical and Technical Systems, Warszawa, 111- 116

11. Talati F., Jalalifar S. (2009) Analysis of heat conduction in a disk brake system, Heat Mass Transfer, Vol. 45, No. 8, 1047-1059.

12. VanSant J. H. (1983) Conduction heat transfer solutions, CA: Lawrence Livermore National Laboratory, University of California, Livermore.

13. Yevtushenko A., Kuciej M. (2009) Temperature in a frictionallyheated ceramic-metal patch and cast iron disc during braking, Numerical Heat Transfer, Part A: Applications: An International Journal of Computation and Methodology, Vol. 56, No. 2, 97-108.

14. Yevtushenko A., Kuciej M. (2012) One-dimensional thermal problem of friction during braking: The history of development and actual state, International Journal of Heat and Mass Transfer, Vol. 55, No. 15-16, 4148-4153.

Acknowledgment: The work has been supported by the European Union in the framework of European Social Fund through the Warsaw University of Technology Development Programme. 